\title{
Effects of topography, soil type and forest age on the frequency and size distribution of canopy gap disturbances in a tropical forest
}

\author{
E. Lobo ${ }^{1,2}$ and J. W. Dalling ${ }^{1,3}$ \\ ${ }^{1}$ Department of Plant Biology, University of Illinois, Urbana, IL 61801, USA \\ ${ }^{2}$ DMCii, Guildford, GU2 7AG, Surrey, UK \\ ${ }^{3}$ Smithsonian Tropical Research Institute, Ancon, Panama City, Panama \\ Correspondence to: J. W. Dalling (dalling@illinois.edu) \\ Received: 18 March 2013 - Published in Biogeosciences Discuss.: 23 April 2013 \\ Revised: 10 September 2013 - Accepted: 23 September 2013 - Published: 1 November 2013
}

\begin{abstract}
Treefall gaps are the major source of disturbance in most tropical forests. The frequency and size of these gaps have important implications for forest ecosystem processes as they can influence the functional trait distribution of tree communities, stand-level aboveground biomass and productivity. However, we still know little about the relative importance of environmental drivers of gap disturbance regimes because existing studies vary greatly in criteria used for defining gaps, in the spatial extent of the study area, and the spatial resolution of canopy height measurements. Here we use lidar (light detecting and ranging) to explore how forest age, topography and soil type affect canopy disturbance patterns across a 1500 ha tropical forest landscape in central Panama. We characterize disturbance based on the frequency distribution of gap sizes (the "gap size distribution"), and the area of the forest affected by gaps (the "gap area fraction"). We found that slope and forest age had significant effects on the gap size distribution, with a higher frequency of large gaps associated with old-growth forests and more gentle slopes. Slope and forest age had similar effects on the gap area fraction, however gap area fraction was also affected by soil type and by aspect. We conclude that variation in disturbance patterns across the landscape can be linked to factors that act at the fine scale (such as aspect or slope), and factors that show heterogeneity at coarser scales (such as forest age or soil type). Awareness of the role of different environmental factors influencing gap formation can help scale up the impacts of canopy disturbance on forest communities measured at the plot scale to landscape and regional scales.
\end{abstract}

\section{Introduction}

In most tropical forests, the main cause of disturbance is the creation of openings in the forest canopy when one or multiple trees fall (Swaine and Whitmore 1988). However, comparisons across forests indicate that differences may exist in the area of the forest affected by gap disturbance (the "gap area fraction"), and in the frequency distribution of gap sizes (Fisher et al., 2008; Baker et al., 2005; Chambers et al., 2009; Foster et al., 2008; Lertzman et al., 1996). Across forests the frequency distribution of gap sizes often follows a powerlaw probability distribution (Kellner et al. 2009; Fisher et al. 2008), however the exponent of this relationship, $\lambda$, which is related to the ratio of small gaps to large gaps, often varies among forests (Kellner and Asner, 2009).

As yet, the environmental factors that lead to variation in the gap area fraction and frequency distribution remain unclear. In part, this is because published studies vary in the criteria used for defining gaps (range 2-15 m minimum canopy height), in the spatial extent of the study area $(0.5-$ $100 \mathrm{ha}$ ), and in the sampling intensity and spatial resolution of canopy height measurements (Kellner et al., 2009; Marthews et al., 2008; Brokaw 1985; Lawton and Putz 1988; Chandrashekara and Ramakrishnan 1994; Jans et al., 1993; Ferreira de Lima et al., 2008; Kapos et al., 1990). Consequently, we still know little about the relative importance of the environmental drivers of variation in canopy disturbance.

Developing an understanding of the processes that shape forest-wide disturbance regimes is important for three reasons. First, different gap disturbance patterns are likely to influence the functional trait distribution of the tree 
community, with a larger fraction of species adapted to higher light conditions in more disturbed forests. Gap disturbance may also affect forest diversity via the intermediate disturbance hypothesis, if higher disturbance frequencies permit the persistence of light-demanding tree and liana species that would otherwise be excluded from forests with lower rates of canopy turnover (Molino and Sabatier, 2001; Schnitzer and Carson, 2001, Sheil and Burslem, 2003).

Second, disturbance-related differences in functional trait composition are likely to influence stand-level aboveground biomass (AGB), either by affecting the relative frequency of fast-growing, light-demanding species, and therefore the stand-level mean wood specific gravity, or via a relationship between AGB and the stem size distribution (Chave et al., 2004, 2005). In support of this view, AGB has been observed to increase from west to east across the Amazon basin in concert with decreasing rates of forest turnover (the mean of mortality and recruitment rates of trees in the stand), declining soil fertility, and increased wood-specific gravity (Quesada et al., 2012; Baraloto et al., 2011).

Third, while measurements of forest turnover rate are labor intensive, and are restricted in scale to forest plots $<100$ ha, measurements of canopy disturbance using remote sensing provide an indirect measure of turnover rate at much larger scales. Early detection of the effects of global change phenomena on rates of forest turnover, for example via more frequent drought-induced tree mortality (e.g., Phillips et al., 2010), or more rapid growth, maturation, and mortality of trees under elevated $\mathrm{CO}_{2}$ (e.g., Korner 2004) will require monitoring forest stands at much larger spatial scales than currently encompassed within plot networks.

In addition to problems arising from diverse criteria used to classify gaps, comparative studies also conflate effects of the external drivers to forest disturbance, e.g., storm frequency (Espirito-Santo et al., 2010) and rainfall regime (Foster and Brokaw, 1982), with intrinsic environmental factors that may also influence the probability of treefall e.g., soil type (Vandermeer et al., 1994; VanderMeer and Bongers, 1996; Ashton and Hall, 1992), topographic position (Poorter et al., 1994), and forest age (Numata et al., 2006). In this study, we provide the first analysis at the landscape scale of how forest age, topography and soil type influence gap disturbance patterns in a tropical forest. We combined existing data on soil type and forest age, with topographic and canopy height data measured using lidar (light detection and ranging) to map the location, size and shapes of canopy gaps across Barro Colorado Island (BCI), Panama.

We hypothesized that if an old-growth forest contains greater variance in tree sizes, including emergent trees that create particularly large gaps, then forest age would be the primary driver of variation in the gap size distribution. In contrast, we hypothesized that variation in soil type and topography would mostly influence the fraction of the landscape in gaps if soil depth and wind exposure influence the susceptibility of trees to windfall, rather than the size of the eventual gap formed. Understanding how these environmental factors influence gap formation will be critical to interpreting predicted changes in disturbance regimes and forest turnover rates resulting from global change.

\section{Methods}

\subsection{Study site}

The study was conducted at Barro Colorado Island (BCI), Panama $\left(9^{\circ} 9^{\prime} \mathrm{N}, 79^{\circ} 51^{\prime} \mathrm{W}\right)$. BCI is a 1500 ha island covered with seasonally moist lowland tropical forest. Average annual rainfall is about $2600 \mathrm{~mm}$, with a pronounced dry season between December and April. The western half of the island is old-growth tropical forest (Fig. 1). The eastern half of the island is a mosaic of secondary forests 80 $150 \mathrm{yr}$ old, resulting from cutting and clearing during the late 1800s and the subsequent establishment of some small farm settlements (Foster and Brokaw, 1982). All human disturbances other than those related to scientific research stopped in 1923, when Barro Colorado Island (BCI) was declared a reserve (Leigh, 1999). The geology of BCI is comprised of three main formations (Baillie et al., 2006): the Bohio formation, from the early Oligocene; the Caimito formation, from the late Oligocene; and the andesite cap, from the Oligocene and early Miocene. The topography of BCI is mostly characterized by relatively gentle slopes ( $80 \%$ of the landscape has slope $<8^{\circ}$ ). Two permanent forest plots have been established on BCI; the 50 ha forest dynamics plot (Leigh, 1999) is located in old-growth forest on the andesite cap, and a 25 ha plot is located in secondary forest $100-120 \mathrm{yr}$ old on the Bohio formation (Caillaud et al., 2010).

The BCI forest is characterized by a relatively homogeneous disturbance regime, where occasional convective storms trigger blow-downs (Brokaw 1982). As such, it is representative of large areas of low latitude tropical forest unaffected by cyclones. However, since BCI is an island, disturbance rates may differ at the lakeshore from the forest interior. Therefore a buffer was used to exclude gaps and edge effects within $20 \mathrm{~m}$ of the shore. Overall, most gaps on BCI occur during the wet season, when winds off the lake are light (Brokaw, 1982).

\subsection{Canopy height and terrain data}

Lidar data were acquired with an Optech ALTM Gemini system multi-pulse, scanning laser altimeter (BLOM Sistemas Geoespaciales SLU, Madrid, Spain). The number of returns ranged between 4 and 27 points per square meter. Point clouds were used to generate a Digital Terrain Model (DTM) and Digital Surface Model (DSM) with $1 \mathrm{~m}^{2}$ pixels. Heights were calculated by subtracting elevations from these models. Estimated vertical errors were smaller than $15 \mathrm{~cm}$ (BLOM, unpublished data). The geo-positioning of the 50 ha plot was 
a

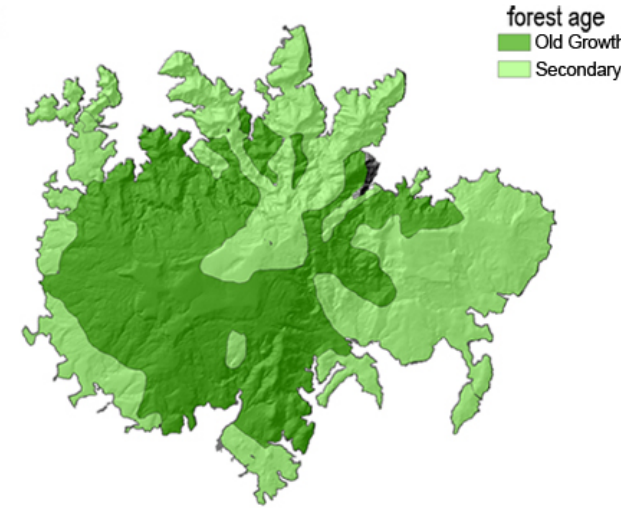

C

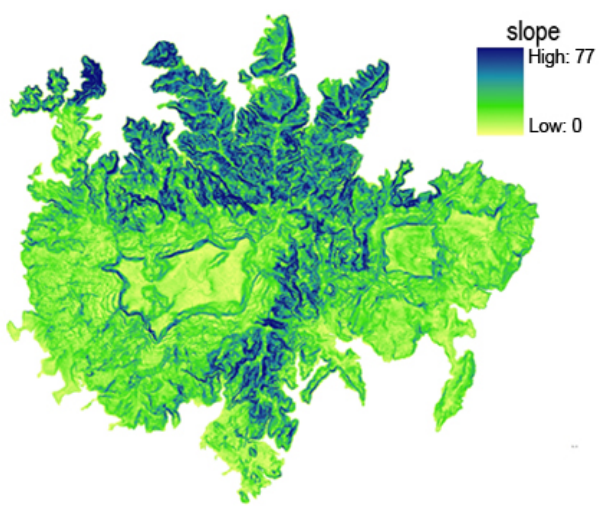

b
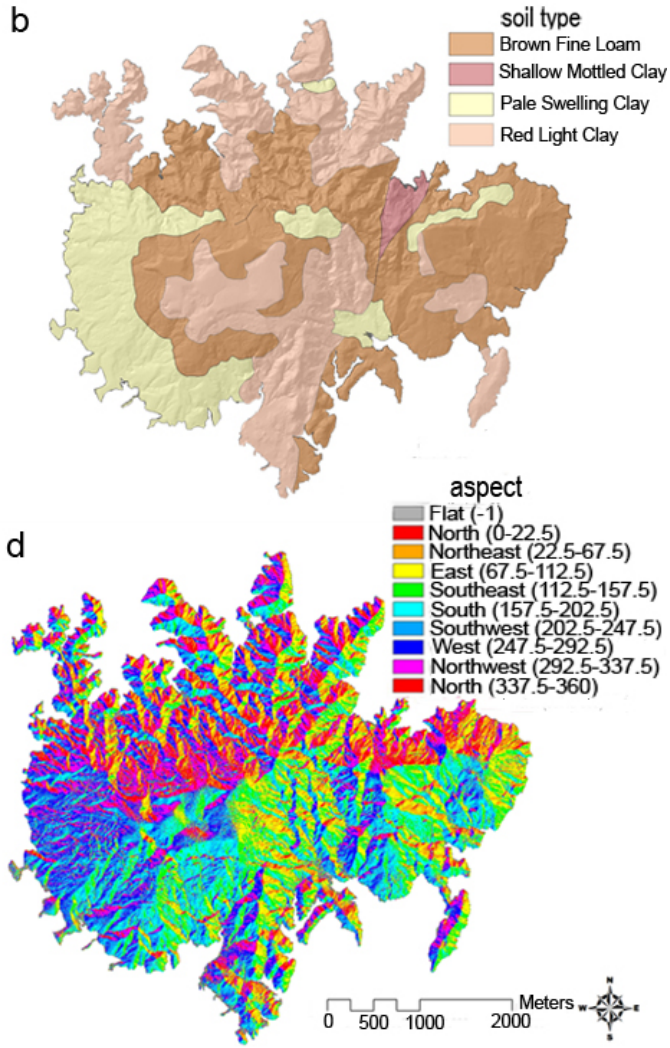

Fig. 1. Spatial distribution of environmental variables with the potential to influence the pattern of gap disturbance across Barro Colorado Island: (a) forest age, (b) soil type, (c) slope, and (d) aspect.

based on the known location of coordinates of the corners (with $<1 \mathrm{~m}$ positional error) (Mascaro et al., 2011).

\subsection{Variables of interest}

\subsubsection{Gap size}

In this study, a gap was defined as all contiguous $1 \mathrm{~m}^{2}$ quadrats with a canopy height $\leq 5 \mathrm{~m}$. Based on this criterion, a canopy gap map was derived for the entire landscape. A $20 \mathrm{~m}$ buffer was applied to the shoreline, so that gaps closer than $20 \mathrm{~m}$ to the shore are not further included in the analyses. This was done to avoid misinterpreting indentations from the water into the land as gaps. Additionally, gaps with an area $<5 \mathrm{~m}^{2}$ were excluded from the analyses, since they are likely to be of little relevance to tree recruitment and forest dynamics. The perimeter, area and geometric center of each gap was calculated. The $5 \mathrm{~m}$ threshold for canopy height was chosen to facilitate comparisons with existing ground surveys of forest gaps (Hubbell et al. 1999), and it results in better correlations with recruitment patterns of gap-dependent species than does a lower height threshold of $2 \mathrm{~m}$ (Lobo, unpublished data). A separate study of the effects of canopy height threshold values on gap disturbance metrics also indicates that the gap size distribution can be studied as a frac- tal with respect to canopy height (Lobo and Dalling, unpublished). Gap areas were calculated by summing the area of contiguous $1 \mathrm{~m}^{2}$ quadrats; here contiguous refers to adjacent quadrats that share a common edge. Quadrats that share a common corner were not considered contiguous.

\subsubsection{Forest age}

A map of forest age was created based on historical records (Enders, 1935). This map originally contained five age classes that were converted to equivalent age classes by 2009 , since no human activities other than those related to research occurred in that time interval. We simplified these age classes into two: old-growth forest $(300-400 \mathrm{yr}$ old; Brokaw and Foster, 1996) and old secondary forest (80 to $130 \mathrm{yr}$ old; Fig. 1). Although there are several discrete patches within each age class, the old-growth forest area is mostly located on the eastern side of the island and the old secondary forest area on the western side. There are two small areas that are in permanently disturbed status: the 4.7 ha laboratory clearing, and a 0.8 ha lighthouse clearing; these areas were not included in our analyses. 
Table 1. Soil types based on texture from the soil survey report by Ballie et al. (2006). Due to the limited extent of the shallow mottled clay soil, it was excluded from subsequent analyses.

\begin{tabular}{|c|c|c|}
\hline Soil type & Morphological features & Extent on BCI \\
\hline Brown fine loam & $\begin{array}{l}\text { Fine loam/clay topsoil, with } \\
\text { little or no clay increase with } \\
\text { depth in stony or bouldery } \\
\text { brown subsoil; mostly }<1 \mathrm{~m} \text { to } \\
\text { saprolite. pH } \mathrm{H}_{\text {water } 5-7 \text {; cation }} \\
\text { exchange capacity (CEC) } \\
11-46 \text { cmolc kg }\end{array}$ & Extensive \\
\hline Red light clay & $\begin{array}{l}\text { Dark brown fine loam topsoil } \\
\text { over red - reddish brown shal- } \\
\text { low and stony clay or fine loam } \\
\text { subsoil; gradual increase in clay } \\
\text { with depth; mostly }>1 \mathrm{~m} \text { to } \\
\text { saprolite. } \mathrm{pH}_{\text {water }} 3.8-6.4 \text {; CEC } \\
\text { mostly } 13-32 \mathrm{cmolc} \mathrm{kg}^{-1}\end{array}$ & Extensive \\
\hline Pale swelling clay & $\begin{array}{l}\text { Dark clay or fine loam top- } \\
\text { soil over variable reddish brown } \\
\text { clay or fine loam over greenish } \\
\text { or bluish light grey or intensely } \\
\text { red/purple mottled heavy clay; } \\
\text { depth }>1 \mathrm{~m} \text {. } \mathrm{pH}_{\text {water }} 4.7-6.3 \text {; } \\
\text { CEC mostly } 14-38 \mathrm{cmolc} \mathrm{kg}^{-1}\end{array}$ & $\begin{array}{l}\text { Extensive on the } \\
\text { western side; } \\
\text { limited elsewhere }\end{array}$ \\
\hline Shallow mottled clay & $\begin{array}{l}\text { Fine loam topsoil }<5 \mathrm{~cm} \text {, over } \\
\text { firm heavy clay; mixed red, } \\
\text { brown and yellow colors with } \\
\text { some grey mottles. Mostly } \\
<1 \mathrm{~m} \text { depth to firm heavy- } \\
\text { textured saprolite. pH } \mathrm{water}_{\text {a }} \\
5.5-6.0 \text {; CEC }>50 \mathrm{cmolc} \mathrm{kg}^{-1}\end{array}$ & Limited \\
\hline
\end{tabular}

\subsubsection{Soil type}

A map of soil type was created based on extensive soil surveys across the island (Baillie et al., 2006). We used the four most common soil forms defined in Baillie's survey, namely brown fine loam, red light clay, pale swelling clay, and mottled heavy clay (Fig. 1; Table 1). Soil type, rather than geomorphological unit, was used as a predictor variable in models as soils reflect underlying geology on BCI (Baillie et al., 2006), and may be expected to influence tree fall via effects on soil texture, hydrology and fertility. We expect that topographic variables (slope and exposure) capture differences among geomorphological units.

\subsubsection{Slope and aspect}

Slope and aspect were calculated across the landscape with $1 \mathrm{~m}^{2}$ spatial resolution from the DTM (Fig. 1). However, we recognize that both variables might affect gap creation probability and gap size at a coarser scale. We calculated slope and aspect at the 25,100 , and $400 \mathrm{~m}^{2}$ scales from the vectorial sum of the slopes or aspects of all $1 \mathrm{~m}^{2}$ pixels within a quadrat of the respective size.

\subsubsection{Exposure}

We calculated three different indices to measure topographic exposure to wind: topex-to-distance (Ruel et al., 2002), 16topex-to-distance, and the visible area (Fig. 2). The topex is calculated by summing the angles of elevation to the visible horizon from a given location in each of the eight cardinal directions. When using topex-to-distance, the distance to the horizon is limited; we used a maximum distance to the horizon of $1 \mathrm{~km}$. To better capture the differences in exposure at areas with complex topography, we defined the 16topexto-distance index by using 16 compass directions instead of 8 and then dividing the outcome by 2 to obtain comparable values. Finally, the visible area index was calculated under the assumption that areas with high visibility will have high exposure to wind and vice versa. The visible area is calculated as the total area visible from a location to the visible horizon in all cardinal directions. Since our forest landscape is located on an island, the forest is surrounded by a flat water surface that might have a different effect on trees from the rest of the terrain in terms of exposure to wind. Consequently, the visible area measure of exposure was further classified 
into exposure to the terrain and exposure to the lake, to assess whether either might have implications for gap creation.

\subsection{Landscape gap model}

\subsubsection{Univariate analysis}

In the first part of the analysis, we considered each explanatory variable independently, to assess its relationship at the landscape level to variation in the frequency distribution of gap sizes, and the gap area fraction. Different approaches were followed for the univariate analyses of categorical and continuous variables. For evaluating the categorical variables, forest age and soil type, the observed gap sizefrequency distribution and gap area fraction were calculated for the entire landscape, as well as for each of the primary and secondary forest areas and each of the soil types. Estimates of the standard error for the gap area fraction of each category were determined by calculating the gap area fraction of 100 randomly generated plots within each class; the area of each plot covered $10 \%$ of the total area for that category. The gap-size distribution for every area was then fit to a power-law probability distribution. In a discrete power law with parameter $\lambda$, the probability for gap size $k$ is given by

$f(k)=c(\lambda) k^{-\lambda}$

where

$c(\lambda) \sum_{i=1}^{n} \frac{1}{k_{i}^{\lambda}}=1$

Lambda $(\lambda)$ is related the ratio of small gaps to large gaps, and is used here as our metric for the size frequency distribution of gaps. Values of $\lambda$ close to 1 indicate a relatively high frequency of large gaps; as the value of $\lambda$ increases, the relative frequency of large gaps decreases. Maximum likelihood estimates (MLE) for $\lambda$ were calculated by minimizing the negative log-likelihood function. We calculated standard errors for $\lambda$, based on the marginal likelihood I, so that

$\mathrm{se}=\frac{1}{\sqrt{I}}$

where

$I=-\left.\frac{\mathrm{d}^{2} L(\lambda)}{\mathrm{d} \lambda^{2}}\right|_{\hat{\lambda}}$

The $95 \%$ confidence intervals were calculated for each estimate of $\lambda$, based on the standard error and a $t$ distribution (Clark, 2007). For each of the categories of forest age and soil type, when confidence intervals of two $\lambda$ estimates were nonoverlapping we considered them to be significantly different.

A generalized linear model (GLM) was used to evaluate the effect of the continuous variables slope, aspect, and wind exposure on the gap size distribution. The gap-size distribution was fit to a Pareto power-law probability distribution. In a Pareto power-law with parameter $\lambda$, the probability for gap size $k$ is given by

$f(k)=\frac{c(\lambda)}{k^{\lambda}}$

where $c$ is determined by

$c(\lambda)=\frac{1}{\int_{a}^{+\infty} k^{-\lambda} \mathrm{d} k}=(\lambda-1) a^{\lambda-1}$

By combining Eqs. (5) and (6) we obtain

$f(k)=\frac{(\lambda-1) a^{\lambda-1}}{k^{\lambda}}$

$\lambda$ depends on the explanatory variable $x$ through the model,

$\lambda=b_{0}+b_{1} x$,

where $b_{0}$ and $b_{1}$ are the GLM parameters.

The parameter estimates of the models were generated using a Markov Chain Monte Carlo (MCMC) approach. The MCMC procedure used 10000 iterations and N-Metropolis for sampling (Hastings, 1970).

Finally, the GLM and MCMC approach was also used to model the effects of the categorical variables on $\lambda$. In this case, a series of dummy variables were used to include all classes of each categorical variable in the model. This was done to assess whether the $\lambda$ estimates calculated with MLE were consistent with the estimates of the GLM using MCMC for the estimation of the parameters. In the absence of an underlying probability distribution, an ordinary least squares (OLS) approach was used to model the effects of the quantitative variables on the gap area fraction. Analyses were conducted using SAS 9.1 (SAS Institute Inc., North Carolina).

\subsubsection{Multivariate analysis}

Following univariate analyses, a multivariate model was created for the gap size distribution using a Bayesian hierarchical framework, including those explanatory variables that had an effect on $\lambda$. Following the same approach used in the univariate analyses of quantitative variables, a GLM was used to model the dependency of $\lambda$ on the multiple explanatory variables, and MCMC was used to estimate the model parameters. The deviance information criterion (DIC) was used to contrast models and DIC weights were used to assess which variables have the greatest contribution to the model. By using the DIC weights we were able to choose the model that had greatest explanatory power and lowest complexity. Finally, we evaluated the chosen model by using a rarefaction analysis in which the model was fit using only $10 \%$ of the gaps; this process was repeated 1000 times, and values and standard errors of the parameters obtained compared to those of the full model. The analyses were conducted in R, using the package 'spatstat' (version 1.31-1). We 
Table 2. Effect of forest age and soil type on the gap size distribution ( $\lambda$ ), and the percent of plot area in gaps (Gap Area Fraction). Means and standard errors are calculated using MLE for $\lambda$ and sub-sampling method for the gap area fraction. The confidence interval of $\lambda$ appears in parentheses next to the mean. The percent of the landscape represented by each category appears is shown in last column. The landscape category comprises the entire island, excluding the shores and the laboratory clearing, with an area of 1484 ha.

\begin{tabular}{|c|c|c|c|}
\hline & $\lambda$ & $\begin{array}{l}\text { Gap Area Fraction } \\
(\%)\end{array}$ & $\begin{array}{l}\text { Landscape Area } \\
(\%)\end{array}$ \\
\hline \multicolumn{4}{|l|}{ Forest age } \\
\hline Primary & $2.01(1.97,2.05)$ & $1.41(0.88,1.94)$ & 42.96 \\
\hline Secondary & $2.11(2.07,2.15)$ & $0.93(0.68,1.18)$ & 57.01 \\
\hline \multicolumn{4}{|l|}{ Soil type } \\
\hline Brown Fine Loam & $2.07(2.03,2.11)$ & $1.01(0.46,1.56)$ & 42.03 \\
\hline Pale Swell Clay & $1.98(1.94,2.02)$ & $1.81(1.10,2.52)$ & 20.61 \\
\hline Red Light Clay & $2.11(2.07,2.15)$ & $0.90(0.55,1.25)$ & 36.13 \\
\hline Landscape & $2.06(2.04,2.08)$ & 1.14 & 100.00 \\
\hline
\end{tabular}

did not attempt a multivariate model for the gap area fraction as this is intrinsically an area-based metric. Thus, while a gap-based approach can be used to model $\lambda$, gap fraction must be calculated from sub-plots. For larger plot sizes that provide unbiased estimates of gap area fraction, the extent of the BCI landscape is insufficient to replicate all combinations of the explanatory variables.

\section{Results}

\subsection{Explanatory variables}

\subsubsection{Forest age}

We observed significant differences in the gap size-frequency distribution and gap area fraction between old-growth and old secondary forest (Table 2), with a higher gap area fraction and a greater ratio of large gaps to small gaps in the old-growth forest. For instance, with a $\lambda$ value of 1.98 we would expect to have 242 times as many gaps of $25 \mathrm{~m}^{2}$ than gaps of $100 \mathrm{~m}^{2}$; by contrast with a $\lambda$ value of 2.11 we would expect to have 347 times as many gaps of $25 \mathrm{~m}^{2}$ than gaps of $100 \mathrm{~m}^{2}$. Differences in the canopy height frequency distribution were also observed between old-growth and old secondary forest, with higher canopy heights and greater heterogeneity of heights in old-growth forest (Fig. 3a). The two permanent forest plots (the 50 ha old-growth plot and the 25 ha secondary plot) had canopy height frequency distributions that were representative of old-growth and secondary forest areas. Nonetheless, the stem size distributions of canopy trees $(\mathrm{dbh}>20 \mathrm{~cm})$ were very similar for the two plots (median diameter of the secondary plot $=29 \mathrm{~cm}$, oldgrowth plot $=30 \mathrm{~cm}$ ).
Given the differences in the gap size-frequency distribution and gap area fraction between old-growth and old secondary forest, forest age was selected as an explanatory variable for the Bayesian hierarchical model that models the gap size-frequency distribution across the landscape. The $\lambda$ values estimated through MLE were consistent with those estimated using MCMC under the GLM model for forest age.

\subsubsection{Soil type}

The gap size-frequency distribution and gap area fraction also differed significantly across the three most widespread soil types (Table 2), with the pale swelling clay soil having the greatest area fraction and the greatest relative frequency of large gaps. Differences in the canopy height frequency distribution were also observed between the three soil types, with the pale swelling clay soil showing a height distribution shifted towards lower canopy heights (Fig. 3b). Consequently, soil type was included as an explanatory variable in the Bayesian hierarchical model that models the gap size frequency distribution across the landscape. The $\lambda$ values estimated through MLE were consistent with those estimated using MCMC under the GLM model for all soil types.

\subsubsection{Slope}

The frequency distribution of slopes was calculated at the 25, 100 and $400 \mathrm{~m}^{2}$ scales (Fig. 4a, d, g). Based on the MCMC estimates of parameters of the GLM model for $\lambda$, there was no consistent relationship between $\lambda$ and slope at the $25 \mathrm{~m}^{2}$ scale (Fig. 4b), while at the $100 \mathrm{~m}^{2}$ and $400 \mathrm{~m}^{2}$ scales, $\lambda$ linearly increased with slope (Fig. 4e, h). The model with slope calculated at the $100 \mathrm{~m}^{2}$ had the lowest DIC value; consequently, slope at the $100 \mathrm{~m}^{2}$ scale was used as an explanatory variable in the Bayesian hierarchical model. The relationship between the gap area fraction and slope was also assessed. The gap area fraction decreased with slope 

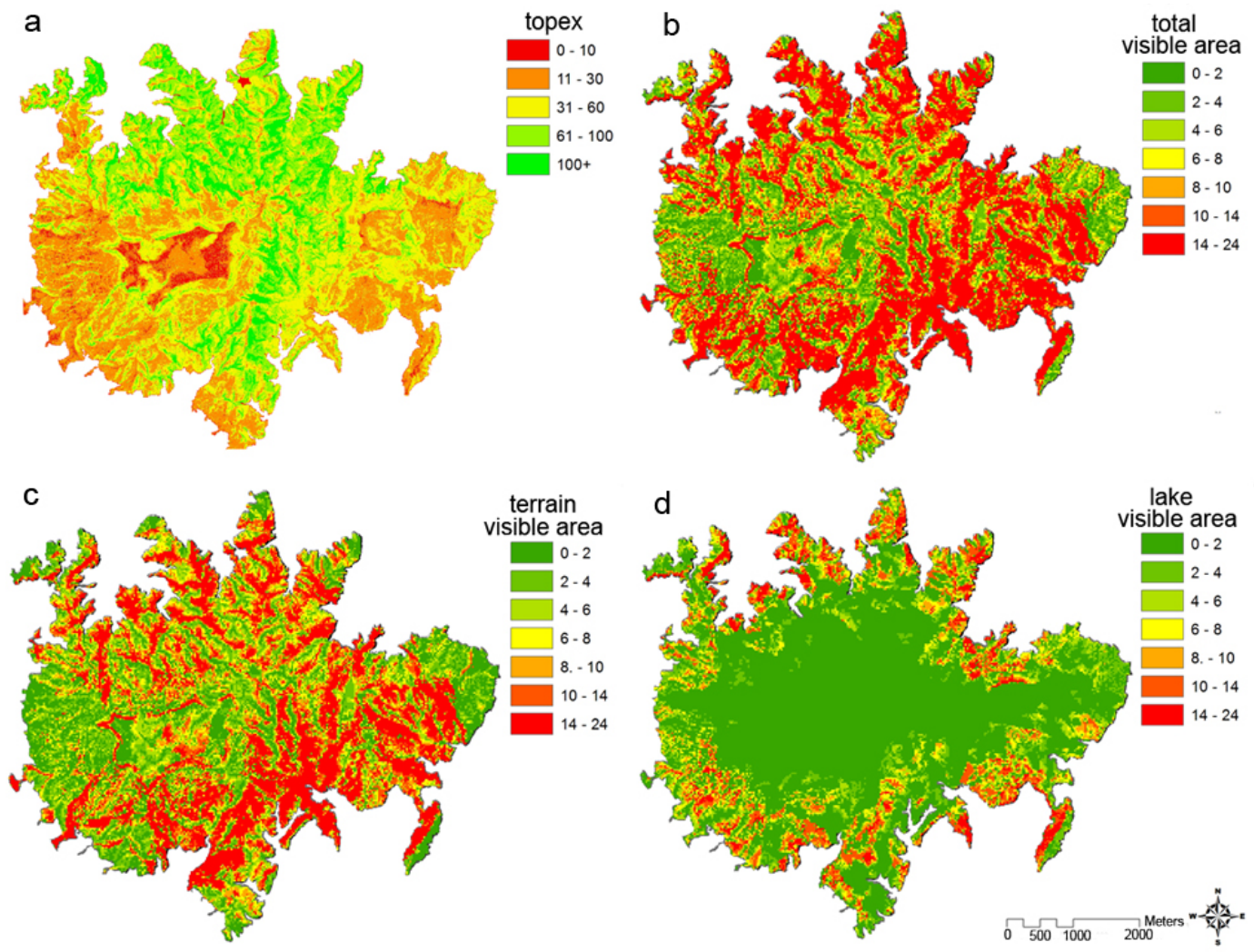

Fig. 2. Spatial distribution of different measures of topographic exposure to wind of the forest across Barro Colorado Island (BCI); these include: (a) topex, (b) total visible area, (c) terrain visible area and (d) lake visible area.

following a power-law function at the 25,100 and $400 \mathrm{~m}^{2}$ scales (Fig. 4c, f, i).

\subsubsection{Aspect}

The frequency distribution of aspect was uniform across BCI (Fig. 5a, d, g). Based on the MCMC estimates for parameters of the GLM model for $\lambda$, there was no consistent relationship between $\lambda$ and aspect at any of the spatial scales measured (Fig. 5b, e, h). Consequently, aspect was not included in the Bayesian hierarchical model that models the gap size frequency distribution across the landscape. At the 25 and $100 \mathrm{~m}^{2}$ scales, the gap area fraction appeared to follow a third order polynomial function (Fig. 5c, f), with a maximum at aspect values of 120 (SE) and a minimum at 300 (W).

\subsubsection{Exposure}

The different indices of exposure used in this study had contrasting frequency distributions across the BCI landscape (Fig. 6). When measuring exposure using topex, the frequency distribution of exposures across the island followed a unimodal distribution that peaked at relatively low topex values, which would indicate higher exposures. Conversely, when measuring exposure using the total visible area index, the frequency distribution of exposures across the island followed a decreasing trend toward higher visible area values, which would indicate a greater frequency of low exposures. The terrain visible area and lake visible area indices were also analyzed but are not represented in Fig. 6, as no consistent effects were observed. Based on the MCMC estimates for parameters of the GLM model for $\lambda$, there was no consistent relationship between $\lambda$ and wind exposure using any of the exposure indices (topex-to-distance, 16topex-to-distance, total visible area, terrain visible area and lake visible area), so none of the indices were included in the Bayesian hierarchical model. The gap area fraction showed no relationship with exposure when using the topex index (Fig. 6c), but was negatively related to the visible area index (Fig. 6f).

\subsection{Gap landscape model}

To identify the most streamlined hierarchical model, a GLM was fit for each explanatory variable using a MCMC approach (Table 3). A model including slope, forest age, and soil type had the lowest DIC weight, but was only one unit lower than the model including slope and forest age only. Consequently, we chose the latter model for its greater simplicity and similar predictive power. Subsequently, we proceeded with rarefaction analyses based on the chosen model. 

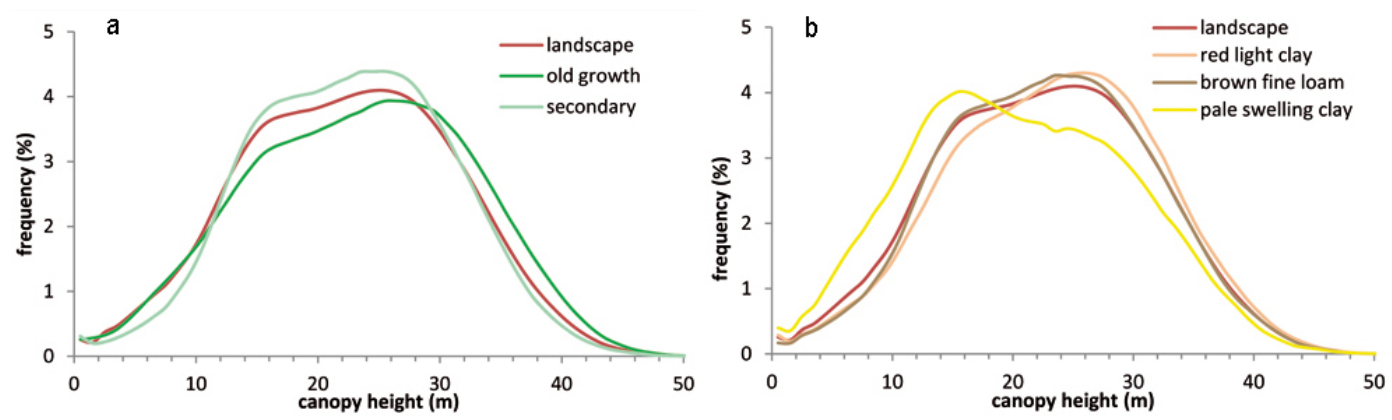

Fig. 3. Differences in the frequency distribution of canopy height between (a) the primary and old-growth forest, and (b) among the three soil types.

Table 3. Hierarchical Bayesian model for the effect of slope, forest age and soil type on the gap size distribution $(\lambda)$ showing means (and standard errors) of each parameter calculated using MCMC and the model deviance information criterion (DIC). For categorical variables the following values were used: old-growth forest $=-1$, old secondary forest $=1$; brown fine loam $=(-1,-1)$, pale swelling clay $=(1,0)$, red light clay $=(0,1)$.

\begin{tabular}{|c|c|c|c|c|c|c|c|}
\hline Variable(s) & Model & $b_{0}$ & $b_{1}$ & $b_{2}$ & $b_{3}$ & $b_{4}$ & DIC \\
\hline slope & $\lambda=b_{0}+b_{1} \times$ slope & $1.90(0.02)$ & $0.07(0.01)$ & - & - & - & 54637 \\
\hline age & $\lambda=b_{0}+b_{1} \times$ age & $2.06(0.01)$ & $0.05(0.01)$ & - & - & - & 54772 \\
\hline soil & $\begin{array}{l}\lambda=b_{0}+b_{1} \times \text { soil }_{1}+ \\
b_{2} \times \text { soil }_{2}\end{array}$ & $2.06(0.01)$ & $-0.07(0.02)$ & $0.06(0.02)$ & - & - & 54757 \\
\hline slope age & $\begin{array}{l}\lambda=b_{0}+ \\
b_{1} \times \text { slope }+b_{2} \times \text { age }\end{array}$ & $1.90(0.02)$ & $0.07(0.01)$ & $0.04(0.01)$ & - & - & 54629 \\
\hline slope soil & $\begin{array}{l}\lambda=b_{0}+ \\
b_{1} \times \text { slope }+b_{2} \times \text { soil }_{1}+ \\
b_{3} \times \text { soil }_{2}\end{array}$ & $1.90(0.02)$ & $0.07(0.01)$ & $0.01(0.01)$ & $0.02(0.01)$ & - & 54636 \\
\hline slope age soil & $\begin{array}{l}\lambda=b_{0}+ \\
b_{1} \times \text { slope }+b_{2} \times \text { age } \\
+b_{3} \times \text { soil }_{1}+b_{4} \times \text { soil }_{2}\end{array}$ & $1.90(0.02)$ & $0.07(0.01)$ & $0.04(0.01)$ & $0.02(0.01)$ & $0.02(0.01)$ & 54628 \\
\hline
\end{tabular}

Rarefaction showed that the effects of slope and forest age were largely consistent with those obtained for the model based on the complete data set: slope always retained a significant effect on $\lambda$, while effects of forest age were not significant in all cases.

\section{Discussion}

Variation in gap disturbance is likely to be an important determinant of species composition, aboveground biomass (AGB) and net primary production in tropical forests (Molino, 2001; Fisher, 2008). The gap disturbance pattern is commonly characterized by two parameters: the area of the forest affected by gap disturbance (the "gap area fraction"), and the frequency distribution of gap sizes. The gap area fraction quantifies the extent of gap disturbance over an area of forest, and is directly linked to AGB; i.e., an increase in the gap area fraction is expected to cause a decrease in $\mathrm{AGB}$, assuming all other factors remain equal. The frequency distribution of gap sizes quantifies the relative frequency of gaps according to size. When the gap-size distribution fol- lows a power-law probability distribution, the exponent $\lambda$ is related to the ratio of small gaps to large gaps; as the value of $\lambda$ increases, the relative frequency of large gaps decreases. Gaps of different sizes are known to have different probabilities of following particular successional pathways. Small gaps are more likely to be filled by growth from adjacent trees, resprouts from trees that survived gap formation, and seedlings of shade tolerant tree species (Whitmore, 1989) whereas large gaps are more likely to be colonized by pioneer trees or lianas (Hubbell et al., 1999; Schnitzer et al., 2000; Dalling et al., 2012). Thus, changes in the gap-size distribution are expected to cause changes in the composition of the forest and AGB.

Our analyses showed that different environmental factors have effects on the gap size distribution and the gap area fraction. When considering each environmental factor separately, slope, forest age, and soil type had significant effects on $\lambda$, while the gap area fraction was also influenced by aspect and exposure. The direction of the effects caused by some of these factors was contrary to our expectations; these effects are explored in greater detail in the sections below. 

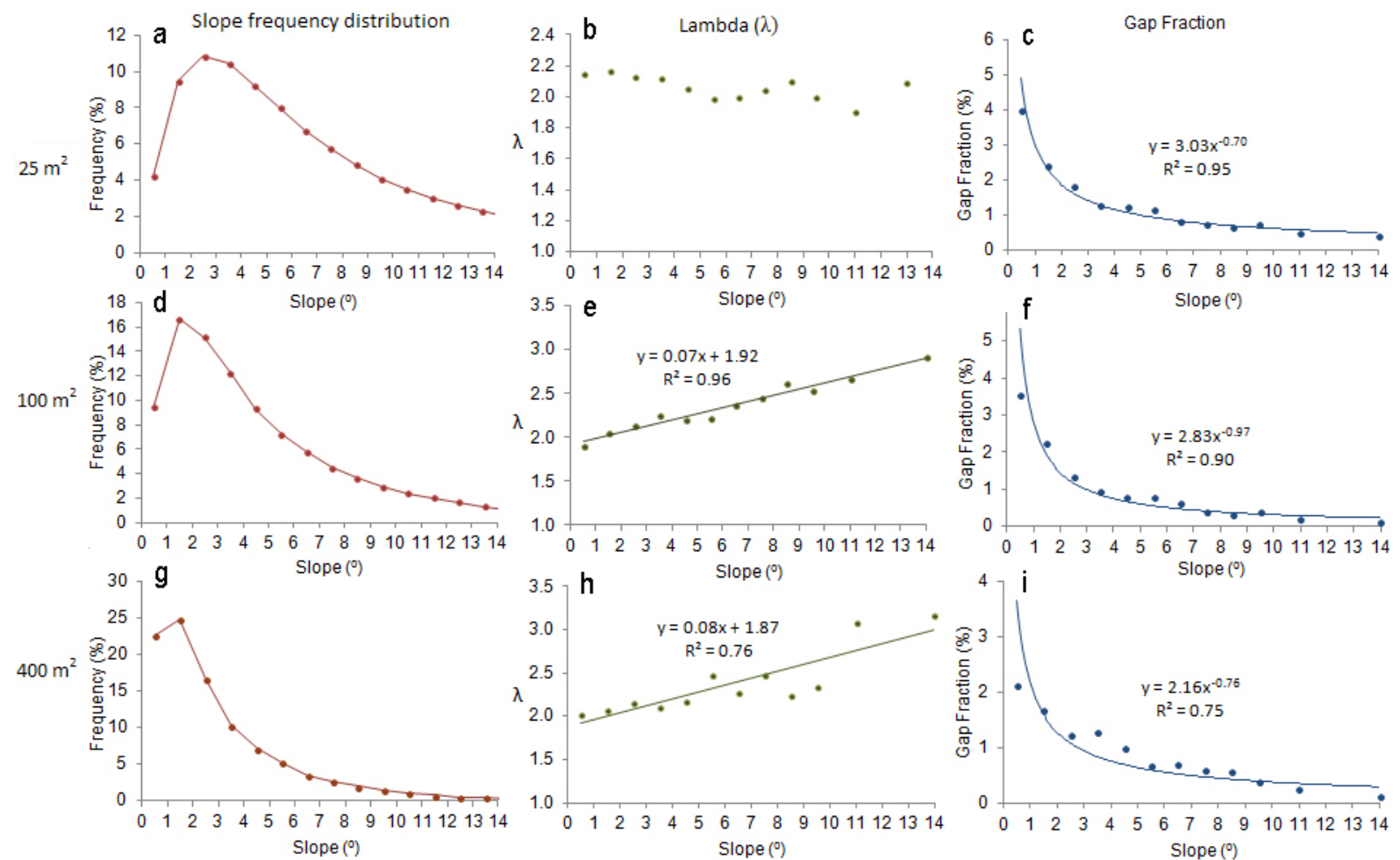

Fig. 4. Frequency distribution of slopes across the landscape $(\mathbf{a}, \mathbf{d}, \mathbf{g})$, gap size-frequency distribution $(\mathbf{b}, \mathbf{e}, \mathbf{h})$ and gap area fraction $(\mathbf{c}, \mathbf{f}, \mathbf{i})$. Slope was evaluated at three different scales: 25,100 , and $400 \mathrm{~m}^{2}$."

\subsection{Determinants of variation in the gap size distribution}

When we considered each explanatory variable separately, we observed that forest age, soil type, and slope had significant effects on $\lambda$, and consequently the gap frequency distribution. The effect of forest age on $\lambda$ agreed with our original prediction that the old-growth forest would have a greater relative frequency of large gaps. We interpret this as a consequence of the greater frequency of emergent trees and the greater heterogeneity of canopy heights in the old-growth vs. the secondary forest. When canopy heights are relatively homogeneous, there is a protective effect with respect to wind exposure from the canopy of neighboring trees; conversely, when the canopy heights of neighboring trees are very different, there may be greater chance of turbulent wind currents causing treefalls, as has been suggested to occur at forest edges and existing gaps (Poorter et al., 1994; Ferreira and Laurence, 1997). Additionally, the greater abundance of lianas in the secondary forest (DeWalt et al., 2000) might partially account for the lower ratio of large gaps, since propagation of tree fall damage to nearby trees might be reduced by the supporting effect of liana tangles. It is worth noting that even though the secondary forest at BCI is $80-130 \mathrm{yr}$ old, and has a similar distribution of tree diameters to the old-growth forest, the differences in the canopy height structure and gap disturbance metrics with the old-growth forest are still measurable.

We did not anticipate the effects of slope and soil type on $\lambda$. The effect of slope on $\lambda$ may seem counter-intuitive, since the greatest relative frequency of large gaps (smallest $\lambda$ ) is found at the lowest slopes. One possible explanation for such a pattern might be a link between slope and hydrology, because plateaus and ridges, which constitute over $40 \%$ of BCI's landscape, have drier soils while steeper slopes retain more moisture during the dry season (Becker et al., 1988). These hydrological properties have been linked to differential mortality rates during droughts on BCI (Condit et al., 1995), with lower mortality rates on moister soils during droughts. Another potential explanation for the smaller gaps observed on slopes is that trees fall before they can get too big, limiting the size of gaps they create. However, canopy height on BCI increases with slope, while the observed pattern of smaller gaps at greater slopes is maintained. These results are most likely only applicable to the range of slopes found at the BCI, where $80 \%$ of the landscape has slopes $<8^{\circ}$. The results observed here may be reversed on steeper slopes, where storms that produce treefalls can also trigger landslides.

The multivariate approach in a hierarchical Bayesian framework used for modeling $\lambda$ as a function of the forest age, soil type and slope showed that the greatest effect was 

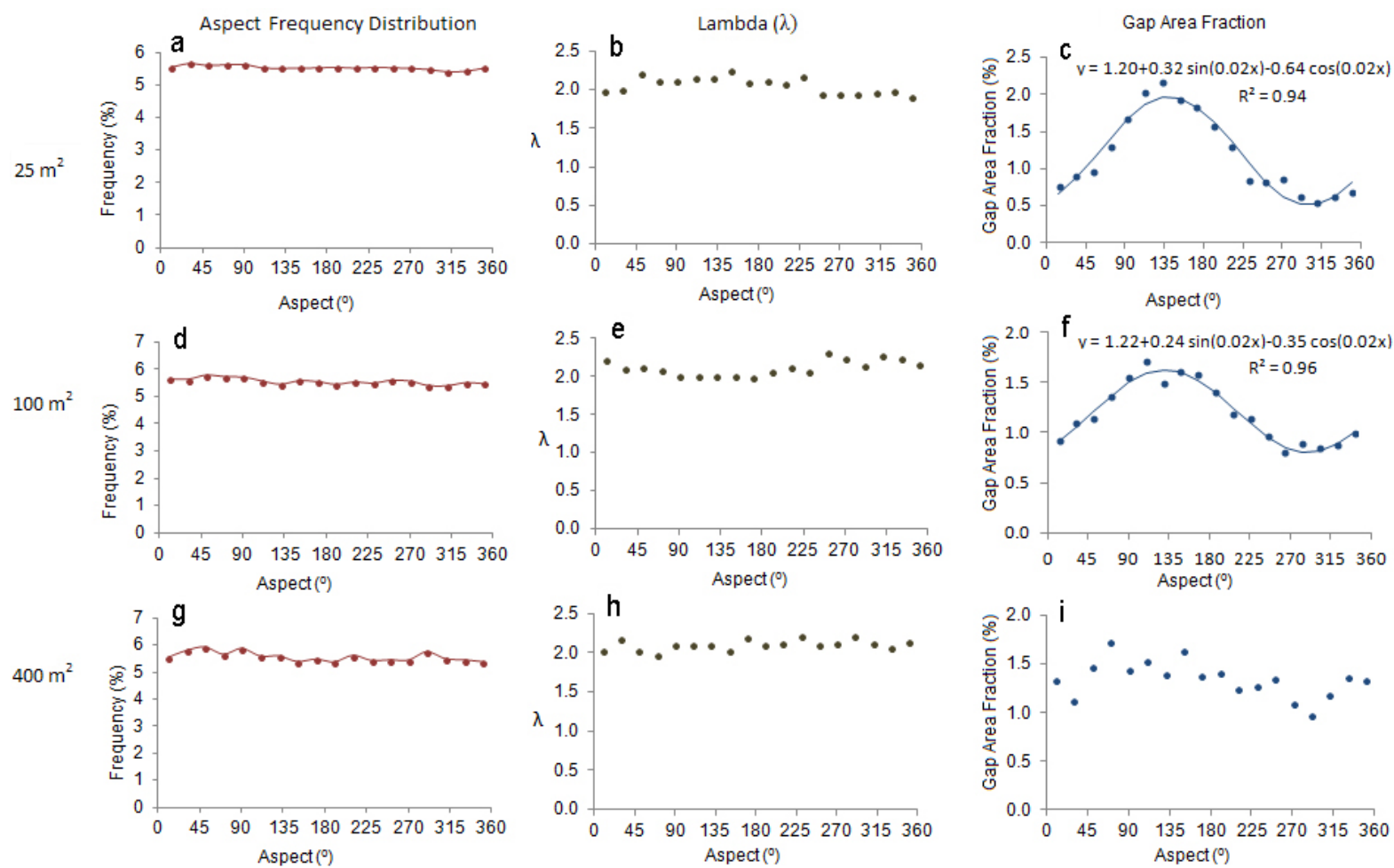

Fig. 5. The frequency distribution of aspects across the landscape (a, d, g) evaluated at three different scales: 25,100 , and $400 \mathrm{~m}^{2}$, and the effect of aspect on the gap size-frequency distribution $(\mathbf{b}, \mathbf{e}, \mathbf{h})$ and gap area fraction $(\mathbf{c}, \mathbf{f}, \mathbf{i})$.
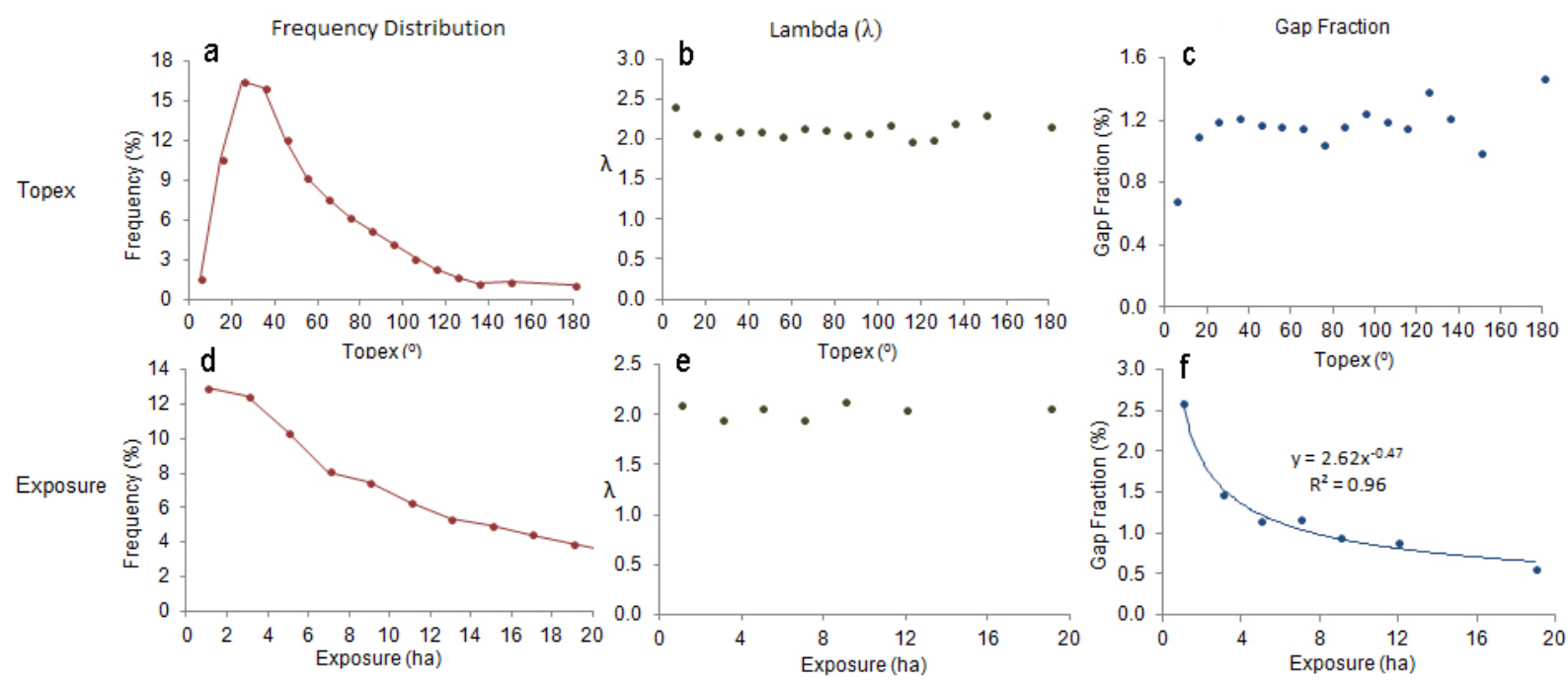

Fig. 6. Effect of topographic exposure on the gap size-frequency distribution (a, d), the frequency distribution of exposures (b, e) and the gap area fraction $(\mathbf{c}, \mathbf{f})$ calculated using two indices of exposure: topex (upper panels) and total visible area (lower panels). 
caused by slope, followed by forest age and marginally by soil type. The most streamlined model for $\lambda$ included only slope and forest age. Furthermore, the rarefaction analyses of the model showed that the effect of slope was strong enough to remain significant even if only $10 \%$ of the data were used, whereas this was not always the case for forest age. However, we should note there are some limitations for distinguishing the contributions of these factors as patches of different aged forest are not distributed evenly across soil types and topographies.

\subsection{Determinants of variation in the gap area fraction}

The different explanatory variables showed several unexpected effects on the gap area fraction. A greater gap area fraction was observed for the old-growth forest than the secondary forest, which, as with $\lambda$, could be caused by differences in the canopy height distribution. This result suggests that, in addition to forming larger treefall gaps, the more heterogeneous canopy height of old-growth forest may increase the risk of wind-related tree falls, or that larger gaps persist on the landscape for longer. Another potential contributing factor could be a higher proportion of old, senescent trees in old-growth than secondary forest. Effects attributed to forest age, however, may also result from differences in soil type, which unfortunately co-vary across the BCI landscape. In particular, the pale swelling clay soil type, which mostly underlays the old-growth forest, had a much higher gap area fraction than the other two.

In agreement with $\lambda$, the gap area fraction also declined with increasing slope following a power-law relationship. This is consistent with the results of Mascaro et al. (2010), who found the greatest accumulation of AGB at BCI occurs on the steeper slopes, suggesting that AGB is constrained by the frequency of gap formation rather than differences in soil fertility. This result may be particular to the relatively gentle slopes found on BCI. Greater gap area fractions at higher slopes have been found for other sites. Poorter et al. (1994) found higher gap area fractions on the upper and middle slope than on the crest or lower slope.

The effects of aspect on the gap area fraction were also somewhat unexpected, with the maximum fraction occurring at a SE aspect. It is worth noting that the effect of aspect on the gap area fraction can only be observed at the 25 and $100 \mathrm{~m}^{2}$ scales and disappears at the $400 \mathrm{~m}^{2}$ scale; this might be an indication that the factors causing tree falls act at relatively fine scales, and thus require similarly fine-scaled studies in order to be detected. Finally, topographic exposure did not show an effect when measured with the more conventionally used topex index, and it showed an effect contrary to our expectations when using the visible area index, with the lowest gap area fractions occurring at the areas with greatest exposure; we can only conclude that this is not an appropriate index to measure wind exposure at BCI. BCI might present unusual complications for assessing topographic ex- posure, because once the shore of the island is reached, the landscape becomes a flat surface with no obstacles for wind. Thus, depending on the extent to which the lake is considered as part of the landscape, conventional calculations of exposure indices may either under or overestimate exposure. It seems likely our visible area index might have overestimated exposure near the shores and consequently caused an apparently decreasing gap area fraction with increasing wind exposure.

\section{Conclusions}

The diversity of effects on the metrics of gap disturbance shown here suggests that variation in disturbance patterns across the landscape is a result of multiple factors acting at the same time and in different ways. Our results also indicate that on BCI, slope plays a critical role in shaping the gap disturbance patterns across the landscape and we presume that this may be a general case in tropical landscapes with similar slope ranges. We expect that slope will also play an important role in sites with steeper slopes, but with opposing effects, as found by Poorter et al. (1994). We also observed that forest age can have a lasting effect on disturbance patterns, even when the stem diameter distribution and basal area approaches that of old-growth forest. Finally, according to our results variation in disturbance patterns appears to be linked to factors that act at the fine scale (such as aspect or slope) as well as factors that show heterogeneity at coarser scales (such as forest age or soil type). Detection of alterations to forest disturbance regimes associated with global change will need to account for these landscape-level determinants of canopy gap formation.

Acknowledgements. This study was funded by NSF grant 0939907 , and with additional support from the Smithsonian Tropical Research Institute, University of Illinois, University of California Los Angeles, and Clemson University. We thank G. Z. Gertner for assistance with data analysis and Joe Wright and Patrick Jansen for providing the 25 ha plot data set.

Edited by: M. Williams

\section{References}

Ashton, P. S. and Hall, P.: Comparisons of structure among mixed Dipterocarp forests of north-western Borneo, J. Ecol., 80, 459481, 2009.

Baillie, I., Elsenbeer, H., Barthold, F., Grimm, R., and Stallard, R.: A semi-detailed soil survey of Barro Colorado Island, Panama, Smithsonian Tropical Research Institute, 54 pp., 2006.

Baker, P. J., Bunyavejchewin, S., Oliver, C. D., and Ashton, P. S.: Disturbance history and historical stand dynamics of a seasonal tropical forest in western Thailand, Ecol. Monogr, 75, 317-343, 2005. 
Baraloto, C., Rabaud, S., Molto, Q., Blanc, L., Fortunel, C., Hérault, B., Dávila, N., Mesones, I., Rios, M., Valderrama, E., and Fine, P. V. A.: Disentangling stand and environmental correlates of aboveground biomass in Amazonian forests, Glob. Change Biol., 17, 2677-2688, 2011.

Becker, P., Rabenold, P. E., Idol, J. R., and Smith, A. P.: Water potential gradients for gaps and slopes in a Panamanian tropical moist forest's dry season, J. Trop. Ecol., 4, 173-184, 1988.

Brokaw, N. V. L.: Treefalls: Frequency, timing and consequences in: The Ecology of a Tropical Forest, edited by: Leigh, E. G., Rand, A. S., and Windsor, D. M., Smithsonian Press, Washington DC, USA, 101-108, 1982.

Brokaw, N. V. L.: Gap-phase regeneration in a tropical forest, Ecology, 66, 682-687, 1985.

Caillaud, D., Crofoot, M. C., Scarpino, S. V., Jansen, P. A., Garzon-Lopez, C. X., Winkelhagen, A. J. S., Bohlman, S. A., and Walsh, P. D.: Modeling the spatial distribution and fruiting pattern of a key tree species in a neotropical forest: methodology and potential applications, Plos One, 5, e15002, doi:10.1371/journal.pone.0015002, 2010.

Chambers, J. Q., Robertson, A. L., Carneiro, V. M., Lima, A. J., Smith, M. L., Plourde, L. C., and Higuchi, N.: Hyperspectral remote detection of niche partitioning among canopy trees driven by blowdown gap disturbances in the Central Amazon, Oecologia, 160, 107-117, 2009.

Chandrashekara, U. and Ramakrishnan, P.: Vegetation and gap dynamics of a tropical wet evergreen forest in the western Ghats of Kerala, India, J. Trop. Ecol. 10, 337-354, 1994.

Chave, J., Condit, R., Aguilar, S., Hernandez, A., Lao, S., and Perez, R.: Error propagation and scaling for tropical forest biomass estimates, Philos. T. Roy. Soc. B, 359, 409-420, 2004.

Chave, J., Andalo, C., Brown, S., Cairns, M. A., Chambers, J. Q., Eamus, D., Fölster, H., Fromard, F., Higuchi, N., Kira, T., Lescure, J. P., Nelson, B. W., Ogawa, H., Puig, H., Riéra, B., and Yamakura, T.: Tree allometry and improved estimation of carbon stocks and balance in tropical forests, Oecologia, 145, 87-99, 2005.

Clark, J. S.: Models for ecological data: An introduction, Princeton University Press, Princeton, USA, 2007.

Condit, R., Hubbell, S. P., and Foster, R. B.: Mortality rates of 205 neotropical tree and shrub species and the impact of a severe drought, Ecol. Monogr., 65, 419-439, 1995.

Dalling, J. W., Schnitzer, S. A., Baldeck, C., Harms, K. E., John, R., Mangan, S. A., Lobo, E., Yavitt, J. B., and Hubbell, S. P.: Resource-based habitat associations in a neotropical liana community, J. Ecol., 100, 1174-1182, 2012.

Dewalt, S. J., Schnitzer, S. A., and Denslow, J. S.: Density and diversity of lianas along a chronosequence in a central Panamanian lowland forest, J. Trop. Ecol., 16, 1-19, 2000.

Enders, R. K.: Mammalian life histories from Barro Colorado Island, Panama, Bull. Mus. Comp. Zool, 78, 385-502, 1935.

Espirito-Santo, F. D. B., Keller, M., Braswell, B., Nelson, B. W., Folking, S., and Vicente, G.: Storm intensity and old-growth forest disturbances in the Amazon region, Geophys. Res. Lett., 37, L11403, doi:10.1029/2010GL043146, 2010.

Ferreira, L. V. and Laurance, W. F.: Effects of forest fragmentation on mortality and damage of selected trees in Central Amazonia, Cons. Bio., 11, 797-801, 1997.
Ferreira de Lima, R. A., Zanforlin Martini, A. M., Gandolfi, S., and Ribeiro Rodrigues, R.: Repeated disturbances and canopy disturbance regime in a tropical semi-deciduous forest, J. Trop. Ecol., 24, 85-93, 2008.

Fisher, J. I., Hurtt, G. C., Thomas, R. Q., and Chambers, J. Q.: Clustered disturbances lead to bias in large-scale estimates based on forest sample plots, Ecol. Lett., 11, 554-563, 2008.

Foster, J. R., Townsend, P.A., and Zganjar, C. E.: Spatial and temporal patterns of gap dominance by low-canopy lianas detected using EO-1 Hyperion and Landsat Thematic Mapper, Remote Sens. Environ, 112, 2104-2117, 2008.

Foster, R. B. and Brokaw, N. V. L.: Structure and history of the vegetation of Barro Colorado Island. in: The Ecology of a Tropical Forest, edited by: Leigh, E. G., Rand, A. S., and Windsor, D. M., Smithsonian Press, Washington DC, USA, 67-81, 1982.

Hastings, W. K.: Monte Carlo sampling methods using Markov chains and their applications, Biometrika, 57, 97-109, 1970.

Hubbell, S. P., Foster, R. B., O’Brien, S. T., Harms, K. E., Condit, R., Wechsler, B., Wright, S. J., and Loo de Lao, S.: Lightgap disturbances, recruitment limitation, and tree diversity in a neotropical forest, Science 283, 553-557, 1999.

Jans, L., Poorter, L., van Rompaey, R. S. A. R., and Bongers, F.: Gaps and forest zones in tropical Moist Forest in Ivory-Coast, Biotropica, 25, 258-269, 1993.

Kapos, V., Pallant, E., Bien, A., and Freskos, S.: Gap frequencies in lowland rain forest sites on contrasting soils in Amazonian Ecuador, Biotropica, 22, 218-225, 1990.

Kellner, J. R. and Asner, G. P.: Convergent structural responses of tropical forests to diverse disturbance regimes, Ecology Letters, 12, 887-897, 2009.

Kellner, J. R., Clark, D. B., and Hubbell, S. P.: Pervasive canopy dynamics produce short-term stability in a tropical rain forest landscape, Ecol. Lett., 12, 155-164, 2009.

Korner, C.: Through enhanced tree dynamics carbon dioxide enrichment may cause tropical forests to lose carbon, Philos. T. Roy. Soc. B, 359, 493-498, 2004.

Lawton, R. O. and Putz, F. E.: Natural disturbance and gap-phase regeneration in a wind-exposed tropical cloud forest, Ecology, 69, 764-777, 1988.

Leigh, E. G. Jr.: Tropical forest ecology: a view from Barro Colorado Island, Oxford University Press, Oxford, 1999.

Lertzman, K. P., Sutherland, G. D., Inselberg, A., and Saunders, S. C.: Canopy gaps and the landscape mosaic in a coastal temperate rain forest, Ecology, 77, 1254-1270, 1996.

Marthews, T. R., Burslem, D. F. R. P., Phillips, R. T., and Mullins, C. E.: Modelling direct radiation and canopy gap regimes in tropical forests, Biotropica, 40, 676-685, 2008.

Mascaro, J., Asner, G. P., Muller-Landau, H. C., van Breugel, M., Hall, J., and Dahlin, K.: Controls over aboveground forest carbon density on Barro Colorado Island, Panama, Biogeosciences, 8, 1615-1629, doi:10.5194/bg-8-1615-2011, 2011.

Molino, J. F. and Sabatier, D.: Tree diversity in tropical rain forests: A validation of the intermediate disturbance hypothesis, Science, 294, 1702-1704, 2001.

Numata, S., Yasuda, M., Okuda, T., Kachi, N., and Nur Supardi, M. N.: Canopy gap dynamics of two different forest stands in a Malaysian lowland rain forest, J. Trop. For. Sci., 18, 109-116, 2006. 
Phillips, O. L., van der Heijden, G., Lewis, S. L. López-González, G., Aragão, L. E., Lloyd, J., Malhi, Y., Monteagudo, A., Almeida, S., Dávila, E. A., Amaral, I., Andelman, S., Andrade, A., Arroyo, L., Aymard, G., Baker, T. R., Blanc, L., Bonal, D., de Oliveira, A. C., Chao, K. J., Cardozo, N. D., da Costa, L., Feldpausch, T. R., Fisher, J. B., Fyllas, N. M., Freitas, M. A., Galbraith, D., Gloor, E., Higuchi, N., Honorio, E., Jiménez, E., Keeling, H., Killeen, T. J., Lovett, J. C., Meir, P., Mendoza, C., Morel, A., Vargas, P. N., Patiño, S., Peh, K. S., Cruz, A. P., Prieto, A., Quesada, C. A., Ramírez, F., Ramírez, H., Rudas, A., Salamão, R., Schwarz, M., Silva, J., Silveira, M., Slik, J. W., Sonké, B., Thomas, A. S., Stropp, J., Taplin, J. R., Vásquez, R., and Vilanova, E.: Drought-mortality relationships for tropical forests, New Phytol., 187, 631-646, 2010.

Poorter. L., Jans, L., Bongers, F., and van Rompaey, R. S. A. R.: Spatial-distribution of gaps along three catenas in the moist forest of Taï National-Park, Ivory-Coast, J. Trop. Ecol., 10, 385-398, 1994.

Quesada, C. A. , Phillips, O. L., Schwarz, M., Czimczik, C. I., Baker, T. R., Patiño, S., Fyllas, N. M., Hodnett, M. G., Herrera, R., Almeida, S., Alvarez Dávila, E., Arneth, A., Arroyo, L., Chao, K. J., Dezzeo, N., Erwin, T., di Fiore, A., Higuchi, N., Honorio Coronado, E., Jimenez, E. M., Killeen, T., Lezama, A. T., Lloyd, G., López-González, G., Luizão, F. J., Malhi, Y., Monteagudo, A., Neill, D. A., Núñez Vargas, P., Paiva, R., Peacock, J., Peñuela, M. C., Peña Cruz, A., Pitman, N., Priante Filho, N., Prieto, A., Ramírez, H., Rudas, A., Salomão, R., Santos, A. J. B., Schmerler, J., Silva, N., Silveira, M., Vásquez, R., Viera, I., Terborgh, J., and Lloyd, J. Basin-wide variations in Amazon forest structure and function are mediated by both soils and climate, Biogeosciences, 9, 2203-2246, 2012, http://www.biogeosciences.net/9/2203/2012/.
Ruel, J. C., Mitchell, S. J., Dornier M. A.: GIS based approach to map wind exposure for windthrow hazard rating. North. J. Appl. For, 19, 183-187, 2002.

Schnitzer, S. A. and Carson, W. P.: Treefall gaps and the maintenance of species diversity in a tropical forest. Ecology 82, 913919, 2001.

Schnitzer, S. A., Dalling, J. W., and Carson, W. P.: The impact of lianas on tree regeneration in tropical forest canopy gaps: Evidence for an alternative pathway of gap-phase regeneration, J. Ecol., 88, 655-666, 2000.

Sheil, D. and Burslem, D. F. R. P.: Disturbing hypotheses in tropical forests, Trends Ecol Evol, 18, 18-26, 2003.

Swaine, M. D. and Whitmore, T. C.: On the definition of ecological species groups in tropical rain forests, Vegetatio, 75, 81-86, 1988.

van der Meer, P. J. and Bongers, F.: Patterns of tree-fall and branchfall in a tropical rain forest in French Guiana, J. Ecol., 84, 19-29, 1996.

van der Meer, P. J., Bongers, F., Chatrou, L., and Riéra, B.: Defining canopy gaps in a tropical rain forest - effects on gap size and turnover time, Acta Oecol, 15, 701-714, 1994.

Whitmore, T. C.: Canopy gaps and the two major groups of forest trees, Ecology, 70, 536-538, 1989. 